\title{
Ankyrin Repeat
}

National Cancer Institute

\section{Source}

National Cancer Institute. Ankyrin Repeat. NCI Thesaurus. Code C14100.

Ankyrin Repeats are tandem modules of about 33 amino acids. The conserved domain structure has been described as side-by-side anti-parallel alpha helices connected by intervening beta hairpin motifs or as beta, alpha, alpha, beta secondary structures or as an L-shaped beta-hairpin and two alpha-helices. The repeats associate to form a higher order structure. Despite sequence variation, the domain core maintains a stable surface of contact residues to mediate protein-protein interactions. Target protein binding involves contacts by the beta hairpin tips and the helical bundle surface facing the Ankyrin groove. ANK repeats have been identified in over 1700 functionally diverse proteins, primarily from eukaryotes; no common theme among the protein targets has been identified. The Ankyrin cytoskeletal protein is composed almost entirely of these repeats. 